\title{
5
}

\section{Rebalancing equity and efficiency for sustained growth}

\author{
Justin Yifu Lin
}

Income distribution is currently one of the most conspicuous problems in China. Since the reforms of 1978, China has maintained rapid economic growth, with an average gross domestic product (GDP) growth rate of 9.7 per cent per annum and a yearly foreign trade growth rate of 17.4 per cent. Growth was particularly strong between 2003 and 2007, during which time China maintained a high GDP growth rate of more than 10 per cent and a foreign trade growth rate of 28.5 per cent per annum. As a country in rapid transition, however, many social and economic problems have developed as the reform deepens. For example, through the end of the 1980s and into the early 1990s, the reform of state-owned enterprises (SOEs) was one of the key talking points in the Chinese economy. It was acknowledged publicly that one-third of SOEs were in deficit, another onethird were known to be in deficit (but this fact was not acknowledged), while only the remaining third were turning a profit. The profitability of SOEs is no longer the main problem in China, as many of the small SOEs have been privatised and the larger SOEs are earning healthy profits. The key issue now is how to improve the competitiveness of SOEs in the global market. A further example of the transition in China's economy is its financial system, which was once very fragile, and which carried a high ratio of non-performing loans. This issue was particularly serious in the four state-owned banks. After several years of reform, however, the ratio of non-performing loans has decreased significantly in the four state-owned banks, and three of them have introduced strategic investors and are listed publicly. Moreover, the stock-market has experienced a full cycle, with a bull market emerging in 2006 and 2007. 
While the old problems were solved, new ones have emerged. With the disappearance of the original chief concerns about the Chinese economy, those concerns that were traditionally of only secondary importance are now centre stage. First, investment is growing too quickly, leading to insufficient consumption. The growth rate of investment in fixed assets was 27.7 per cent in 2003, 26.6 per cent in 2004, 25.7 per cent in 2005 and 24 per cent in 2006. More importantly, such high investment growth rates were reached with a very low inflation rate. In the national income account, too much investment leads to a level of consumption that is insufficient to sustain economic growth. In the past five years, China's investment grew faster than its comparatively high increases in consumption of 10 per cent per annum, leading to a sharp accumulation of production capacity. In this case, consumption becomes insufficient when matched with this increase in productive capacity. China needs to export more in order to deal with its excessive production capacity. This is why China has experienced a high growth rate in exports and a rapid accumulation in its foreign trade surplus during recent years. This is a new problem for China.

Second, too many capital and resource-intensive industries have been developed. China's growth is highly dependent on resources. According to Ma Kai (2007), chair of the National Development and Reform Commission of China, in 2006, China contributed 5.5 per cent of global GDP, but it used 15 per cent of the world's energy, 30 per cent of the world's steel and 54 per cent of the world's concrete. Unemployment is another problem for developing capital-intensive industries. Since 1980, although the Chinese growth rate has been very high, the ability of the Chinese economy to create employment has been continually decreasing. The main reason is that China has developed too much capital-intensive industry rather than building up those industries that are labour intensive.

Third, investment has been concentrated mainly in just a few industries. This situation was especially serious in 2003 and 2004. I call this the 'wave phenomena' (Lin 2007a), highlighting that investment tends to wash into certain industries like waves, often leaving the industry with an excess capacity to produce. Take the Chinese steel industry as an example: in 2007, the country's productive ability reached 450 million tonnes, whereas it was only 190 million tonnes in 2002. While China needed to import a great deal of steel in the past, now it is essential for China to export it.

Moreover, there is excess liquidity in the Chinese economy. Large banks usually hold excess reserves. This reduces the effectiveness of monetary policy. Chinese experts usually argue about whether interest management or gross management should be the monetary tool. In some cases, interest management 
is not as effective as gross management-for instance, when changing the reserve ratio. Because of the existence of excess reserves, raising the reserve ratio sometimes has little influence on credits.

Furthermore, a bubble plagues the real estate market. It is reasonable policy to make real estate the pillar of industry in China. On one hand, surplus labour in rural areas will move into urban areas as a continuation of urbanisation, which will lift the demand for housing; on the other hand, as income levels grow, larger, more expensive houses are demanded by those already living in cities. The demand for real estate is therefore, and will continue to be, high. Property developers in China tend, however, to contradict the normal experience of house construction patterns in industrialised economies. According to this experience, small houses are generally in demand at the first stage of development. When income levels rise, people begin to upgrade the size of their houses and, as a result, there is higher demand for larger properties. The current trend in the Chinese real estate market, however, is for the widespread construction of large houses with insufficient numbers of smaller abodes under construction. This trend must be reversed.

Apart from these, many new social problems have emerged. Among them, income disparity is one of the most notable (Lin and Chen 2007a, 2007b, 2008; Lin 1999, 2005; Lin and Liu 2003). In 1978, the ratio of urban disposable income to rural net income was 2.6:1; this ratio grew to 3.3:1 in 2006. China now has one of the biggest income gaps between urban and rural areas in the world. Simultaneously, a large group of low income-earning citizens has emerged in the larger cities because of widespread unemployment (Lin and Liu 2003). At present, China's Gini coefficient exceeds 0.45 , which means it has passed the 'safe line' for social stability, according to many experts. There are, however, many other problems emerging in China, such as incomplete services in health care and the educational system, the prices of which are too high compared with income levels.

Living conditions have improved greatly thanks to the high economic growth rate during the past years. Basic shortages of food and clothing have been solved, even in provincial areas. Social discontent is, however, spreading, largely because of the social problems mentioned above. As the old adage suggests, 'shortage is not a problem, but inequality really matters'. When the income gap becomes more significant, many kinds of problems and contradictions arise. Many people even think that conditions in the past were better than those today. In the past, although they were very poor, people felt content because incomes were more equal; now, however, even though people are generally richer than previously, inequality is causing widespread discontent. 
There have been many appeals to cure the problem of income disparity, and redistribution is usually suggested as the tool. In a discussion about personal income tax in 2005 and 2006, for example, many people suggested that China should raise its tax rate for the rich as a way of subsidising low-income groups in the form of transfer payments. The highest personal income tax rate in China has, however, already reached 45 per cent-one of the highest tax rates in the world. Considering this, I would suggest that the main problem with China's tax system is with enforcement, not the rate itself. Critics of this viewpoint express an important social sentiment-that is, many people are unhappy because they believe that some people in China are too rich. This is not, however, the case. Compared with other countries, the rich in China are not rich at all; therefore, we still need to activate the rich to create more social wealth-at least in the present. It is our task to ensure that in the course of development, the income of the poor grows faster than that of the rich, but it should not be accomplished by redistribution.

Under these conditions, it is very difficult to build a harmonious society. Based on the characteristics of the current stage of economic and social development, the Communist Party of China formulated a policy of 'advancing with the times', and put forward a 'scientific concept of development' at its sixteenth National Congress, the contents of which included two key points. On one hand, development should be the ultimate policy goal; on the other hand, in the course of development, we must try to achieve 'five areas of coordination': coordination between urban and rural areas, between regions, between society and the economy, between humans and nature, and between domestic and international markets. At the seventeenth National Congress in 2007, the party put forward a policy of building a harmonious society (Hu 2007), in order to resolve livelihood issues, including education and health-care difficulties, the gap between urban and rural areas, social security and so on. The government's working reports from 2007 and 2008 have put forward many concrete policy measures to solve these livelihood issues.

\section{Comparative advantage: realising equality and efficiency simultaneously}

How does one carry out the scientific concept of development and simultaneously construct a harmonious society in China? The current guidelines for policymaking dictate that primary distribution emphasises efficiency, and redistribution solves equality. This statement suggests that since China aims to emphasise individual livelihoods and social harmony, the Chinese government should play a more active role in realising equality through distribution. 
However, this course of action will be unproductive, if not counterproductive, if we fail to realise equality and efficiency simultaneously in primary distribution and, instead, resort only to redistribution. Equality and efficiency should be realised simultaneously in primary distribution, and redistribution, acting as a complementary tool, should solve the residual problems left by primary distribution. It is worth emphasising that in certain circumstances, redistribution can be helpful. In the current system, however, primary distribution emphasises efficiency and redistribution solves equality, which means simply that we should not take the equality problem into consideration in the process of primary distribution. This, it seems, is counterproductive.

Can China really achieve its aim of realising equality and efficiency simultaneously in primary distribution?

Such a policy has at least two meanings. First and foremost, China must maintain a high economic growth rate in order to ensure sustainable growth of average personal incomes. After 29 years of rapid growth, the average personal income in China reached US $\$ 2,400$ in 2006. This is still very low, reflecting 4-5 per cent of the average personal income in the United States. This suggests that China should continue to emphasise efficiency to speed up economic growth. The second meaning of China's policy is that the country must ensure that incomes for the poor grow faster than those for the rich in the course of economic development, in order to realise equality and efficiency simultaneously.

The question remains, is there a path to the realisation of equality and efficiency through initial distribution? The answer is yes. The imperative is to develop according to China's comparative advantage. If China can choose the industries, products and technologies that are suitable to its comparative advantage, it will be able to improve the distribution conditions and realise the 'five areas of coordination' put forward in its scientific development concept, while at the same time maintaining a high economic growth rate (Lin et al. 1999; Lin 2004a, 2004b, 2004c, 2007b).

The discussion about comparative advantage has lasted for more than 20 years, with some arguing that China should adopt a competitive advantage as opposed to the traditional comparative advantage. This is a mistaken view of the concepts. In fact, competitive advantage is based on the notion of comparative advantage. Failing to follow comparative advantage means that competitive advantage cannot be achieved. Mike Porter (1990), a professor at the Kennedy School at Harvard University in the United States, first put forward the concept of competitive advantage. He argued that four factors determined competitive advantage: first, whether the country had relatively lower prices of 
a type of resource compared with the international price-that is, the country had a resource price advantage. In this case, the country should utilise its price advantage and develop industries intensively using the competitive resource instead of other resources. Second, did the developing industry have a large enough domestic market? Where a new industry can rely on high domestic demand, it will have a much better chance of being internationally competitive. Third, does the new industry enjoy a good clustering effect in the home country, which can improve its efficiency? Finally, can the new industry enjoy a competitive domestic market, instead of one that is monopolistic?

Among the four determining factors mentioned by Porter (1990), there are really only two independent factors: the scale of domestic markets and factor prices. The scale of the domestic market is largely fixed, being determined by population size and income levels. In the domain of factor prices, Porter (1990) argues that we must take full advantage of the resources with price advantage, where the price advantage really equates to comparative advantage. The remaining two factors are determined inherently by the price advantage. First, the industrial clustering effect cannot be achieved unless the industry has a comparative advantage. For example, the electronic-processing industry cannot be clustered in the United States as it is in Dong Wan, China, because this industry is highly labour intensive and wages in the United States are very high. Similarly, capital-intensive industries cannot be clustered in these countries, because interest rates in developing countries are high due to the shortage of capital. Second, only industries with comparative advantage can form a competitive domestic market. Without comparative advantage, government protection and subsidies are needed in order to build the industry-therefore, competitive markets cannot develop. All this leads to the conclusion that the competitive advantage theory, in nature, refers only to two basic factors: comparative advantage and the scale of the domestic market.

This leads to the question of which of the two factors is more important? Doubtless, it is good to have a large domestic market; however, if a country follows its comparative advantage, its products can be sold on the international market. In this case, the scale of the domestic market matters little. For example, Finland, whose population is only a little more than five million, has companies that sell predominantly to the international market instead of to the relatively small domestic market (examples include Nokia). Therefore, we can see that competitive advantage is based on comparative advantage, and economies with a competitive advantage can grow rapidly and achieve 'high efficiency'.

Generally speaking, China's market advantage remains its abundance of lowpaid workers. Accordingly, many labour-intensive industries can be developed 
easily, including manufacturing, services and the segments of capital-intensive industries that are relatively labour intensive. Further job opportunities can therefore still be created. On the other hand, competitive power and market share can be increased if China develops according to its comparative advantage, and more profits can be realised. With a surplus, the country can speed up capital accumulation and the capital can be deepened rapidly because the growth of the labour force is relatively steady because of China's restrictions on population growth. The country will change its factor endowment gradually from being a labour-abundant country to one that is capital abundant. This transitional process is also typical in the development history of industrialised countries. When capital becomes abundant and labour becomes relatively scarce, the price system begins to function and wages grow, while interest rates decline. This results in depreciation of the assets of the rich (those with capital) and appreciation of the assets of the poor (low wage earners). As a result, income distribution begins to even out. For example, after World War II, some countries, including Japan, Taiwan, Korea and Singapore, continually improved their income distribution through rapid economic development (and they have since been dubbed the 'East Asian miracles'). Many empirical studies that demonstrate this effect (see, for example, Lin, Cai and Zi 1999b).

In the discussion about comparative advantage, some commentators worry that China might have difficulty developing if its focus remains on labourintensive industries whereas industrialised countries develop capital-intensive industries. This is, however, a misunderstanding of the situation. Development is achieved in stages. Leap-frogging a stage of development could result in a complete failure to develop; in contrast, moving step by step can lead to rapid development. Industries in industrialised countries are mostly capital and technology intensive, while industries in developing countries are mostly labour and resource intensive. Different industrial structures are, however, the result of natural endowments, not the causes. Industrialised countries are relatively rich in capital but short of labour, so the price of capital is low but the price of labour is high. In order to maintain competitive power, industrialised countries have no choice but to substitute labour for capital by developing capital and technologically intensive industries. The United States has protected its labourintensive industries such as textiles. If, however, China exports more in these industries, it will hurt the industrial-country markets. Why? Because wages in the United States are much higher than in China, which leads to relatively high production costs in labour-intensive industries in the United States. In contrast, wages in China are relatively low and the industries with competitive power are therefore the labour-intensive ones. It is said that Chinese industries 
currently lack competitive power; this is not the case. If Chinese industries lack competitive power, why do other countries always raise 'dumping' complaints against China? The industries with comparative advantage are always competitive.

Since competitive advantage is based on comparative advantage, for China to catch up, it is important that it upgrades its endowment structure more quickly than its competitors. Generally, there are three components of factor endowment: capital, labour and natural resources. Because natural resources are relatively fixed, upgrading the factor endowment structure means that China must increase per capita capital rapidly. China can catch up with the industrialised countries over time if its per capita capital increases faster than in industrialised countries. If developing countries continue to grow according to their comparative advantage, their factor endowment structure can be upgraded rapidly and they will, as a result, reach the same level of development as industrialised countries. The logic employed here is simple, but powerful. Output can be used for either current consumption or accumulation of capital. The ratio of output used for accumulation is determined largely by the rate of return on capital. High rates of return on capital lead to high ratios of accumulation. At the early stage of development, the rate of return on capital is very high in developing countries because of the general shortage of capital, leading to a high capital accumulation rate.

A further advantage specific to developing countries is that they are less technologically advanced than industrialised countries (Lin 2003). On the surface, this seems to be a clear disadvantage; however, several gains are afforded from not being at the forefront of technological advancement. Using this advantage, developing countries can upgrade their industries continuously and the return rate on capital does not therefore decrease (or decreases only very slowly). Under these conditions, the capital accumulation rate in developing countries can remain continually higher than the rate in industrialised countries. The industries with the biggest potential for technological 'catch-up' are those that use existing technologies and produce products with established demand, and this means that developing counties can introduce new technologies, absorb them and re-innovate at very low cost. As a result, technology can be updated frequently, leading to a slow decrease or even stable rate of return on capital. The capital accumulation rate will also remain high in developing countries. In contrast, technology in industrialised countries is positioned at the frontier of the global technology chain, so invention and innovation drive development with high costs and high probability of failure. Although industrialised countries hold most of the world's patents, their industries and technologies update more 
slowly than in developing countries because the latter are less technologically advanced and can take advantage of the industrialised world's technology. This is why industrialised countries typically have a lower rate of return on capital and a lower propensity to invest compared with developing countries. After 10-20 years, or at most two generations, the average levels of capital per capita in developing countries can catch up with those in industrialised countries. By making full use of comparative advantage and the technological gap, for example, East Asian countries successfully shortened the gap or even caught up with industrialised countries within only one generation during the 1960s and 1970s.

Several years ago, I put forward a concept I called 'run fast with small steps'. This means that a developing country needs to keep each step of its industrial and technological upgrading fairly small, but it must also ensure that the frequency of upgrades is high. The goal, in China at least, should be to catch up with industrialised countries within two to three decades, or even within one generation. Most people see high-technology industries only in industrialised countries and low-technology industries only in developing countries. The level of industry and technology certainly influences national power and the income levels of a country and, as a result, this leaves some hoping that the process of development can be achieved through shortcuts. This catch-up strategy, however, which aims to develop industries and technology as quickly as possible, cuts across the grain of comparative advantage.

Industrialised and developing countries have distinct comparative advantages and therefore industries with comparative advantage in industrialised countries might not be suitable for developing countries, such as China. If developing countries adopt a catch-up strategy - that is, they set up capital-intensive industries across the board-these industries will lack competitive power in the international market. This leads to inefficient resource allocation across the whole economy, which in turn leads to low efficiency in economic development and a range of other problems, including over-concentration of capital and reductions in levels of employment. Moreover, a large number of low-income wage earners are shut out of the labour market and cannot share the fruits of economic development, which leads to an increase in explicit and implicit unemployment. Worse still, since industries under comparative advantagedefying strategies have no competitive power in an open and competitive market, they can survive only if protection and subsidies shield the industries from competition. Governments invest in capital-intensive industries in centrally planned economies, but in market economies, only the rich can do this. 
This begs the question, where are the subsidies coming from? They will come, directly or indirectly (through taxes, subsidy policies and so on), only from people who do not invest in the capital-intensive industries-namely, the poor. Providing subsidies to the rich by extracting from the poor will lead to a worsening of income and wealth distribution. Without the adoption of a permanent-residency registration policy, as used in some countries, the rural unemployed swarm into big cities and form slums because they cannot enter the formal employment market. Of course, developing countries can set up several high-level industries, large companies and brands, as can be found in industrialised countries, but the profits of these industries, by and large, come from government protection and subsidisation, which is a kind of wealth transfer rather than real value creation by the firms. The labour force would be better served by working in labourintensive industries that have comparative advantage, but they cannot do this because there is not enough capital to work with. Since wealth transfer and the uncompetitive capital-intensive industries create nothing, the remaining capital that can be funnelled into labour-intensive industries is meagre. Ironically, it is these industries that have the potential to create the highest levels of wealth for the developing country's economy. Furthermore, this slows increases in the factor endowment as well as economic growth.

Developing countries that adopt this inappropriate catch-up strategy share the following common economic path: in the beginning, the economy grows rapidly through investment, which is protected and subsidised by the government. As time passes and investment slows, economic growth slows and the country begins to seek foreign capital, which is followed by a short period of rapid growth. The result is that the country is left with industries that cannot create wealth but which have drawn on large foreign loans that must be repaid. If they fail to repay these debts, financial and social crises are inevitable. Moreover, the potential exists for the so-called 'bad market economy' to rear its ugly head. Industries developed under this catch-up strategy need protection and subsidisation from the government; in market economies, however, people who invest in these industries prefer to seek more protection and subsidisation from the government rather than enhancing productive efficiency. This leads to a large number of rent-seeking activities in these economies.

After World War II, Latin America adopted the 'import substitution' strategy, developing various capital-intensive industries, which amounted essentially to a catch-up strategy. This approach to development resulted in a lack of employment, unequal distribution of public finance and the emergence of slums in big cities. Under the resulting conditions of social disharmony and mass unemployment, Latin American governments moved towards 'democratic 
politics', in which they put forward appealing, populist social welfare policies. This led to large fiscal deficits and financial crises. These issues have continued to plague the development of Latin American countries to this day.

The current distribution system in China emphasises efficiency in primary distribution; however, China does not define efficiency by competitive market power without government protection and subsidisation. Firms that benefit from protection and subsidisation enjoy high profit levels. Essentially, however, these profits are a kind of wealth transfer that will inevitably lead to social instability. If China seeks to solve its equity problem through redistribution, it will risk slumping like Latin America. Therefore, I do not agree with the theory that 'primary distribution emphasises efficiency, and redistribution solves equality'. Rather, I believe that equity and efficiency problems should be solved through the primary distribution of wealth and that redistribution should only complement this.

Equity and efficiency can be realised simultaneously by adopting a comparative advantage-following strategy for development. 'Comparative advantage' is a term used by economists, but which of China's industries are really in accordance with its comparative advantage? China's factor endowment structure is changing and improving. Labour-intensive and capital-intensive industries are relative concepts and there are large factor differences between the regions of China: coastal regions such as Shanghai and Shenzhen; inland regions such as Anhui, Jiangxi, Hunan and Hubei; and western regions such as Xinjiang, Ningxia and Gansu. How can development best utilise comparative advantage, taking these vastly differing experiences into account? From the viewpoint of an entrepreneur, profits are more important than the concept of comparative advantage. Profits are determined by the prices of products and factors. Developing according to comparative advantage requires a perfect price system rather than the development of industries according to comparative advantage. The price system must sufficiently and flexibly reflect the relative scarcity of every factor in the factor endowment structure. If a factor is relatively rich, its price is relatively low and vice versa. If the velocity of a factor's accumulation is relatively large, implying that it changes from being relatively scarce to relatively abundant, its price will decrease from relatively high to relatively low, and vice versa. If such a price system is established, entrepreneurs will use relatively cheap factors to minimise costs and maximise profits in competitive markets. Consequently, setting up a sufficiently competitive market system is vital. Development following comparative advantage leads to a high velocity of capital accumulation. Through this, an upgrade of products and technologies leads to an upgrade of industries 
from labour intensive to relatively capital and technology intensive. In this development process, income distribution will be in labour's favour.

The aim of the reforms in China is to set up a perfect socialist market economy. Because China has developed according to comparative advantage, it has been maintaining fast growth for more than two decades since the beginning of the reforms and the era of openness. In the era of the planned economy, the Chinese government ignored comparative advantage and developed various capital and technology-intensive industries. To set up these industries, the government depressed factor prices artificially, which led to a shortfall of capital. The government then allocated scarce capital to favoured industries through administrative measures. China adopted a gradual process of reform from 1978 onwards. The government now provides some protection and subsidisation for industries that have no comparative advantage while, at the same time, it places some constraints on those industries that have comparative advantage and that enjoyed preferential pricing in the past. Consequently, economic stability is obtained while the economy secures rapid growth. At present, China is the world's third-largest trading country and exports predominantly labour-intensive goods; however, as the economy grows and capital accumulates, the capital and technological composition of export products is increasing. This is the necessary stage of development that follows on from comparative advantage.

The gradual process of reform also creates some issues. Thus far, China is yet to set up a sufficiently competitive market system. The government continues to intervene in the allocation of certain resources. This is a hangover from the era of protection and subsidisation provided to industries without comparative advantage. The distortions leading to these issues are discussed below.

\section{Distortions of financial structures}

Before the reform period began, there were no banks or stock-markets in China. After the reform, the government began to develop and perfect the financial system; however, the main task of the financial system during that period was to serve large firms. The process of appropriating funds from government was replaced by bank loans in 1983, meaning that firms could no longer appropriate national public finance but instead had to secure loans from banks at low interest rates. The low-interest loans played the role of subsidisation. To meet the large firms' needs, the government kept depressing interest rates. Meanwhile, the government set up large state-owned banks to provide subsidies for the large SOEs. The current financial system in China, which has inherited aspects of the previous system, comprises mainly the four large state-owned banks. The 
amount of RMB held by these four banks as a proportion of total RMB used in the financial system is 75 per cent. These four banks provide loans to the large firms. In addition, the stock-market has begun to develop. Of course, the firms that had the capacity to enter the stock-market were the larger firms in the market. Labour-intensive firms utilising comparative advantage are mainly small and middle-sized. Under this highly concentrated financial system, small firms cannot access finance from banks through loans, which restricts their development, and this in turn reduces employment opportunities. All of these factors lead to the following four wage problems.

First, a large number of middle-sized and small firms in labour-intensive industries, such as manufacturing and services, cannot receive financial support. According to the results of an industry survey in 2004, there were 39.2 million individual firms in China. Today, however, the number has fallen to 25.8 million. The drop is due partly to the fact that some small and medium-sized firms experience normal closures, mergers and transfers. A large proportion of these firms, however, disappear because they cannot access enough finance. Second, almost all rural households cannot obtain financial support. As a result, the problem highlighted above is equally prevalent in rural areas. Developing modern agriculture requires financial support. Setting up a plastic canopy costs 10-20,000 yuan and a modern henhouse costs more than 100,000 yuan. Peasants do not have these sums of money and have great difficulty obtaining loans from banks. Therefore, industries that should be able to profit from comparative advantage cannot access the necessary financial support. Meanwhile, capital is over-abundant, which means that the allocation of capital is inefficient. Third, employment creation is relatively insufficient. On one hand, there are high rates of unemployment in rural areas; on the other, a large number of excess rural labourers cannot transfer out. This is the main reason for the growth in income inequality within cities, and between cities and rural areas. Fourth, capital is over-intensive. The firms able to borrow money from banks are generally the larger, former state-owned enterprises and large private businesses that emerged after the reforms began. These firms can borrow money at a fairly low cost (the current interest rate for loans in China is 6 per cent, which is lower than in industrialised countries). These firms will naturally invest capital into capital-intensive industries, which is also the main cause of the over-intensification of capital. Since sufficient employment cannot be realised and those with excess capital (the rich) invest with subsidies, income distribution suffers. Given this, since the marginal propensity of consumption (MPC) of the rich is low while the MPC of the poor is high, the economy will suffer from insufficient consumption due to poor income distribution. 
Many social phenomena are related to income distribution inequality. If the banks' capital is over-concentrated, it is easy to see a 'wave phenomenon' in investment because in industrial economies, it is not easy to judge which industries will be profitable. As with the case of the Internet in the 1990s, everyone believed it would be profitable and capital flowed into all types of Internet businesses. This led to overblown prices and the bubble finally burst, with dramatic effects. This phenomenon occurs every one or two decades by accident in industrialised countries. Developing countries can, however, avoid these shocks to the system by learning from the experiences of industrialised economies, and using them as a guide. This means that large amounts of money are injected into particular industries and investment tends to concentrate in that industry. This continuing investment builds on itself within the industry, thus forming the wave phenomenon. Distortions in the financial structure can be a big problem and, if not adjusted, the problems of income distribution might also remain unresolved.

\section{Distortion of prices of resources}

In China's formerly planned economy, the prices of capital and resources were depressed artificially. Once the reform process began, China set about adjusting these price distortions; however, only some distortions have been dealt with. During the 1990s, fees and taxes on resources, when taken together, accounted for 1.8 per cent of resource prices. This has led to two problems. First, the deregulation of resource prices, particularly for coal, petroleum, copper and iron ore, resulted in convergence with international price levels. These prices are therefore much higher than before. As the resource sector increased in value, the fees and taxes as a proportion of resource prices fell to 0.5 per cent. The second issue it that while mining firms were once state-owned, in the mid 1980s the sector was opened up to private and foreign-owned companies. As a result of high resource prices and relatively low taxes, the resource sector has become highly profitable. While the value of the exploitation of a resource can be upwards of 10 billion yuan, the cost of securing these rights from Chinese authorities is only tens of million yuan, which equates to about 1 per cent. Consequently, those who receive these rights can reap substantial profits. Several concerns arise from the disparity between the high private earnings of resource companies and the low incomes derived from them. First, income distribution is further skewed in the direction of inequality. Second, as local governments decide on resource exploitation rights, social values are damaged and adverse rent-seeking activities are common. Finally, corrupt practices and corner-cutting in the mining industry tend to lead to poor practices and frequent accidents. 


\section{The administrative monopoly}

Market monopolisation poses some serious problems for the Chinese economy. Monopolisation tends to be exercised mainly by SOEs in sectors such as electricity services, telecommunications and, in some cases, education. Revenue derived from monopolistic activities is retained by firms and not passed on to the national treasury. This has a distortional effect and further contributes to income disparities. Where primary distribution does not solve the equity problem, the Chinese government lacks the incentive or ability to undertake redistribution to close income gaps. This has come about because reform is incomplete and because development strategies that defy comparative advantage have been followed. If China is able to improve its reform strategy, equity and efficiency can be realised through primary distribution. The remaining issues, such as incomplete markets, asymmetrical information, economies of scale and social security, can be solved through redistribution.

\section{Specific measures}

What are some of the ways in which China can achieve equity and efficiency simultaneously through primary distribution? First, reform of the market economy needs to be deepened and, most significantly, the financial structure must be improved. Market economies achieve productivity through a combination of capital and labour. China's most competitive industries tend to be labour intensive, generally in manufacturing or services. The proportion of the tertiary, or services, industry as a part of China's GDP decreased from 40 per cent in 2006 to 39.5 per cent in 2007, due mainly to insufficient capital support to the services industry. Moreover, the large number of rural households that cannot obtain financial support and thus modernise their agricultural practices contributes to the slowing of the tertiary sector.

From the experience of industrialised countries, it is clear that banks tend to begin small and, as development takes hold, increase in size. In the early stages of economic development, labour-intensive industries dominate the market and, as a result, small and medium-sized banks service small and medium-sized firms. As development progresses and capital in the economy increases, so does the scale of firms, as banks and stock-markets emerge. Chinese reform has, however, been predominantly top down, meaning that the State has set up large-scale SOEs, which are served by state-owned banks and stock-markets. The trouble is that there are no small or medium-sized financial institutions to service the loans of smaller enterprises. To overcome this problem, China must develop its small and medium-sized financial sector to encourage the growth of small firms. At present, the Chinese government has begun to allow 
the establishment of small rural banks, which it is hoped will meet the needs of rural households. This represents a healthy step forward for the Chinese economy (Lin et al. 2006).

There are, however, issues arising from the design of this policy. First, the threshold conditions for setting up a small bank are too low-set at just RMB500,000. Moreover, one of the key articles of regulation states that any new bank must jointly operate with an existing commercial bank which must hold at least 20 per cent stock shares of the new bank. This is difficult to realise in practice. It is certainly prudent to ensure that new banks are well backed; however, it is still difficult for rural households to access loans because of the continued reluctance of the commercial lenders to provide rural loans. The regulations demand that commercial banks buy 20 per cent of the shares in the new bank, which means that these larger banks take on a considerable financial responsibility in the performance of the smaller, rural-focused banks. This erodes any incentive to lend to rural households. As a result of the legislation, the goal of setting up a small banking sector is compromised. For the sector to function properly, two things must change. First, the entry threshold must be raised by between RMB10 and 50 million. This could be coupled with a requirement that each loan be backed by greater collateral in the form of assets. Second, strict supervision should be imposed on the sector.

The second specific measure that China should undertake to achieve efficiency and equity through primary distribution is to impose a significant tax on resources. As mentioned above, the taxes and fees on resources amount to only 1.8 per cent. In the United States, however, such royalties account for 12 per cent of resource prices and tax on petroleum drilled from US waters is set at 16 per cent. In addition, quantity imposition of tax must be replaced by an ad valorem system: when the price of a product rises above a certain level, a high rate of profit tax should be imposed to keep profits reasonable. There are, however, difficulties in designing an appropriate policy to achieve this because the former state-owned mining companies bear a heavy social burden, propped up by government subsidies provided through lower taxes and fees. In contrast, there is a range of private firms that have no social burden. The most effective solution to this imbalance is for the Chinese government to shed the social responsibilities from state-owned enterprises and impose resource taxes according to the law of the market economy.

Finally, the Chinese government should focus on cancelling administrative monopolies and should begin strengthening supervision of monopolistic industries into which competition cannot be introduced. Once competition is introduced into monopolistic industries, prices will go down and profits will be lower. In those industries in which competition is not suitable, such as the 
electricity industry, the government must strengthen its supervision of prices, costs and revenue allocation.

If these three aspects can be achieved successfully, China will be able to realise equity and efficiency simultaneously in primary distribution. Income differences between urban and rural regions will decline once a complete market system is fully in place. The main reason for the superabundance of liquidity is that small firms are unable to secure loans and large firms have a great deal of unutilised capital due to restrictions on investment. Furthermore, as the number of middle-sized and small banks in China increases, the issue of superabundant liquidity will decline, income distribution will become more equitable, the marginal propensity of consumption will increase and incentives for investment will decrease.

\section{Functions of the government under a development strategy that pursues comparative advantage}

If China follows a strategy of comparative advantage, industries with comparative advantage can produce for export while the products of industries without comparative advantage can be imported. This will balance international and domestic markets. Under such a strategy, protection of industry will no longer be required because Chinese firms will be competitive in world markets. This will also reduce rent-seeking activities and reduce adverse effects on social values. The government will still have an important role to play. The Chinese government should focus on the activities that are generally undertaken by market economy governments, as well as attending to certain unique functions that are essential for developing-economy governments.

First, the Chinese government should take responsibility for education services. If the economy develops through a policy of exploiting comparative advantage, the velocity of upgrades in the industrial and technical structures will be fairly high. This has been the case for certain East Asian economies that have transformed from poor agricultural economies to modernised economies within one or two generations. This has been coupled with an increase in per capita incomes, which now rival those in industrialised economies. To meet the needs of rapid upgrades to the industrial and technical structures, China must produce greater numbers of skilled workers and administrators who can adapt to changes in the market. To achieve this, it is essential that the government invests more in education.

Second, greater attention needs to be directed towards improving the quality of Chinese institutions. The relative backwardness of a developing country is not represented only by its level of economic development; it is 
judged against the level of development of its institutions, particularly its legal and financial institutions. Improvements in institutional quality have explicit positive externalities. This implies that firms will apply sub-optimal quantities of resources to this objective; therefore, to achieve economic development, the government should seek to improve institutional structures and frameworks step by step.

Third, China must develop a social security strategy of sorts. In every economy, there are those who represent a net cost to the economy, such as the aged, children and those individuals without families to support them. Given that these groups cannot always enter the workforce, their survival depends on government support. Through the process of rapid industrialisation, people are more prone to change jobs. During periods of transition from one form of employment to another, those without work will also depend on government support to survive, and this might come in the form of unemployment benefits.

In addition, market failures occur as a result of asymmetrical information, which requires proper government intervention. For example, one might ask the question: why does banking require supervision? The answer is that there is a problem of information asymmetry between the supplier and the purchaser of capital. Without supervision of the system, exploitation is inevitable. Looking further afield, externality issues in areas such as environmental protection will also require government supervision.

Finally, China's government must focus on macroeconomic issues because of the volatility in domestic and overseas markets. This is a significant responsibility for government generally. The phenomenon of 'waves' of investment was discussed above-this happens occasionally in industrialised economies and frequently in developing economies. An important role for government could be to provide signals on the level of investment in particular industries, thus guiding further inflows of capital. This would reduce the severity of over or under-investment. Further areas of government guidance in the economy should be the setting of industry standards, supervision of sectors, such as banking, and setting thresholds for investment.

\section{Conclusions}

It is problematic to suggest that primary distribution emphasises efficiency, and redistribution solves equality, partly because there are problems with how we understand efficiency. It is unreasonable to define efficiency as China's ability to compete in industries in which industrialised countries have an established market share. Furthermore, trying to achieve this type of efficiency fails to 
recognise that China's interests are best served by pursuing industries that make use of comparative advantage. Failing to follow comparative advantage principles will lead to insufficient employment and the widening of income gaps. Meanwhile, if China attempts to solve its equity problem through redistribution, it runs the risk of plunging into the 'Latin America trap'. Consequently, China should realise equity and efficiency simultaneously in primary distribution to promote rapid and healthy economic development. The focus should also be on bridging the income gap within cities, and between cities and rural areas, by lifting employment rates. In doing so, China will be able to avoid the development pattern that concentrates on resources, avert damage to the natural environment and realise the 'five balanced aspects', including unification of markets at home and abroad, and creating a harmonious society.

\section{References}

$\mathrm{Hu}, \mathrm{J} ., 2007$. Hold the great banner of socialism with Chinese characteristics to strive for new victories in building a well-off society, Speech given to the seventeenth National People's Congress of the Communist Party of China, Beijing, 15 October.

Kai, M., 2007. Changing the style of economic growth, realizing rapid and healthy growth, Speech given to Annual Senior Forum on Chinese Development, Beijing, 18 March.

Lin, J.Y. and Chen, B., 2007a. Development strategy, financial repression and inequality, CCER Working Paper, China Center for Economic Research, Beijing.

——, 2007b. Priority to develop heavy industries, urbanization and income disparity between urban and rural areas, CCER Working Paper, China Center for Economic Research, Beijing.

- -, 2008. Development strategy, technology choice and inequality, CCER Working Paper, China Center for Economic Research, Beijing.

Lin, J.Y. and Liu, M., 2003. 'Convergence and income distribution in Chinese economic growth', World Economy, 26(8):3-13.

Lin, J.Y. and Liu, P., 2003. 'Development strategy, equality and efficiency', China Economic Quarterly, 2(2):479-501.

Lin, J.Y., 1999. 'The result of Chinese economic reform and the disparity between different areas', Economic Development Review, 1-2:7-22.

——, 2003. 'Backward advantage or backward disadvantage: a discussion with Yang Xiaokai', China Economic Quarterly, 2(4):989-1,004.

-—, 2004a. Development Strategy and Economic Development, Peking University Press, Beijing. 
-_, 2004b. Development Strategy and Economic Reform, Peking University Press, Beijing.

——, 2004c. Viability, Economic Development and Transition, Peking University Press, Beijing.

- - 2005. Development strategies and regional income disparities in China, CCER Working Paper, China Center for Economic Research, Beijing.

- - 2007a. 'Wave phenomena and the restructure of macroeconomics in developing countries', Economic Research, January.

——, 2007b. Development and transition: idea, strategy, and viability, Marshall Lectures of Cambridge University, 31 October-1 November.

Lin, J.Y., Cai, F. and Li, Z., 1999a. The Chinese Miracle: development strategy and economic reform, Shanghai Sanlianc Bookstore and Shanghai People's Publishing House, Shanghai.

_- 1999b. 'Development strategy and comparative advantage: re-explanation of the East Asian miracle', Chinese Social Science, 5:8-10.

Lin, J.Y., Sun, X. and Jiang, Y., 2006. A primary study on the appropriate financial structure theory in the course of economic development, CCER Working Paper, 6 June, China Center for Economic Research, Beijing.

Porter, M.E., 1990. The Competitive Advantage of Nations, Free Press, New York. 